ECCOMAS

Proceedia
COMPDYN 2021

$8^{\text {th }}$ ECCOMAS Thematic Conference on Computational Methods in Structural Dynamics and Earthquake Engineering

M. Papadrakakis, M. Fragiadakis (eds.)

\title{
RELIABILITY-BASED ASSESSMENT OF A MASONRY ARCH BRIDGE UNDER FLOOD EVENTS
}

\author{
Carlos Mendoza ${ }^{1}$, Mónica Santamaria ${ }^{2}$, Hélder S. Sousa ${ }^{3}$ and José C. Matos ${ }^{4}$ \\ ${ }^{1}$ MSc student, University of Minho, ISISE, Department of Civil Engineering \\ Guimarães, Portugal \\ e-mail: carlosamc1@hotmail.com \\ ${ }^{2} \mathrm{Ph} . \mathrm{D}$. candidate, University of Minho, ISISE, Department of Civil Engineering \\ Guimarães, Portugal \\ email: id8021@alunos.uminho.pt \\ ${ }^{3}$ Postdoc researcher, University of Minho, ISISE, Department of Civil Engineering \\ Guimarães, Portugal \\ e-mail: sousa.hms@gmail.com \\ ${ }^{4}$ Assistant Professor, University of Minho, ISISE, Department of Civil Engineering \\ Guimarães, Portugal \\ e-mail:jmatos@civil.uminho.pt
}

\begin{abstract}
Natural disasters are unavoidable and can cause serious damage to bridges, which may lead to catastrophic losses both human and economic. In the US more than $45 \%$ of bridge collapses are caused by flood events in which more than one-third are caused by scouring effects. In 2015, part of the Tadcaster bridge, a masonry arch bridge in North Yorkshire UK, collapsed during a flooding event. This tragedy was followed by another one in 2019 when a masonry bridge collapsed in the same county. Therefore, the assessment of bridges susceptible to these events is of paramount importance as to identify possible mitigation needs. The objective of the present paper is to present a consistent framework to obtain the reliability index of a masonry arch bridge (MAB), under flood hazard that is subject to local scour, using surrogate models to reduce the computational effort of the probabilistic analysis. The proposed framework is tested on a MAB located in Portugal. A two-dimensional numerical model is constructed where the random variables that affect the structural capacity and the scour geometry were considered. The results show the failure mechanism of the MAB when subjected to scour-induced settlements, therefore allowing to identify the vulnerable zones along the arch's length. The presented methodology can be used to assess the bridge performance under a flood event, thus providing useful information for bridge management and monitoring. Moreover, it can be further developed to include fragility analysis and vulnerability assessment.
\end{abstract}

Keywords: • Masonry bridges, Local Scour, Reliability, Surrogate Models. 


\section{INTRODUCTION}

Bridges have a higher design life than most common structures. During this period, bridge management is fundamental to maintain a satisfactory performance of the structure. To achieve this goal, information regarding the state of the bridges is essential when making decisions that involve the maintenance of the structure [1]. Masonry arch bridges (MAB) represent a large part of the European network (railway and roadway), hence by identifying the safety level of the bridge, suitable maintenance strategies can be applied [2].

Bridges are structures that face harsh environmental condition; therefore, should be able to withstand potential hazards such as flooding, earthquakes, among others [3]. Natural disasters are often unavoidable and can cause serious damage to bridges, which may cause catastrophic losses both human and economic. Floods account for a large percentage of all bridge failures [4]. Nowadays, the effects of climate change may produce larger and more frequent peak river discharges, which could induce the mobilization of sediment from riverbeds, and around piers and abutments (i.e., increased risk of scouring). Bridge collapses have been experienced worldwide. In 2015, part of the Tadcaster bridge, a masonry arch bridge in North Yorkshire, collapsed during a flood event [5]. Therefore, the assessment of bridges susceptible to these phenomena (namely flood, scour, trapped debris, among others) is of utmost importance as to identify possible mitigation needs.

When assessing bridges under loading conditions resulting from environmental conditions, the lack of available information causes high uncertainties when representing the environmental actions and the parameters of the materials [2]. Explicitly considering the uncertainties can mitigate this lack of information. Moreover, limit analysis-based structural assessment in combination with probabilistic-based approaches has been used to predict ultimate loading carrying capacity and safety verification of Portuguese MAB [6]. Thus, a full probabilistic analysis for the reliability-based assessment of MAB under floods for ultimate limit states should be implemented.

Due to the complexity of the probabilistic analysis, the objective of the present work is to propose a consistent framework to reduce the computational costs to obtain the reliability index associated with a failure mode of masonry arch bridges (MAB) under flood hazard. This will allow to assess the performance of bridges that may affect the efficiency of important sections of the roadway network if damaged by a flood event. The proposed framework is tested on a MAB "Ponte da Vala do Carregado" located in Portugal. A numerical model is constructed in LimitState:GEO software (http://www.limitstate.com) [7]. The model implemented the random variables that affect the structure capacity [2] and the scour geometry, such as shape and depth derived from flood conditions [8].

\section{METHODOLOGY}

The methodology considered in this work is shown in Figure 1. First, a numerical model is developed using a software based on limit state analysis. Then, a surrogate model is defined to perform a sensitivity analysis which allows to identify the most influent variables on the ultimate capacity of the bridge [2]. Later, a new surrogate model based on the most relevant variables is introduced which uses a low number of evaluations, thus reducing the computational costs of the full probabilistic analysis [6], [9]. Finally, the reliability index is computed based on the subset simulation technique [10].

For this study, the procedure was implemented for different scour profiles. This approach allows assessing the bridge reliability under local scouring from a case study. 


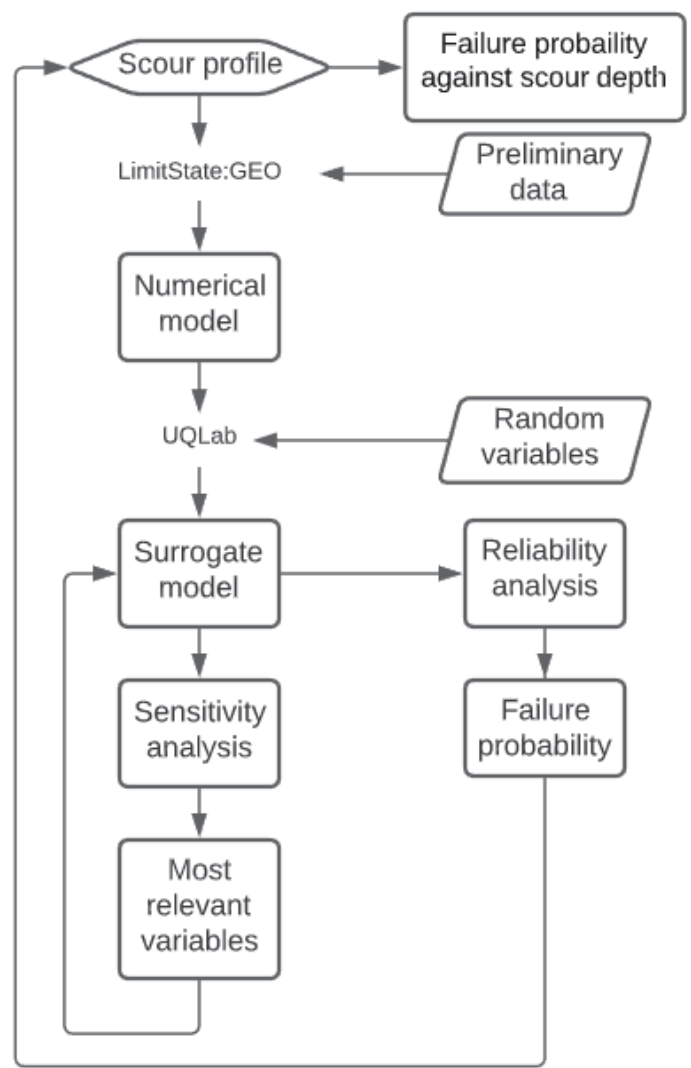

Figure 1: Framework for reliability assessment of MAB under local scouring.

\section{NUMERICAL MODEL}

The case study "Vala do Carregado" is a railway masonry arch bridge located in Vila Franca de Xira, Portugal (see Figure 2). The three-span bridge has a total span of around 30m, and it is supported by direct foundations. Earliest reports of the bridge date from 1881 when the bridge was built. After that, there is information regarding reinforcement of the arch barrel, until subsequent studies were conducted, and it was concluded that the bridge should be replaced [11].

According to the performed studies, it was found that the bridge foundations presented poor soil conditions, which were incompatible with the foundation system, and hydraulic capacity was below the requirements of the design flood (corresponding to a 100-year return period) [11]. For these reasons, the Vala do Carregado bridge before being replaced is considered as representative of the typical Portuguese railway masonry arch bridges which require particular attention.

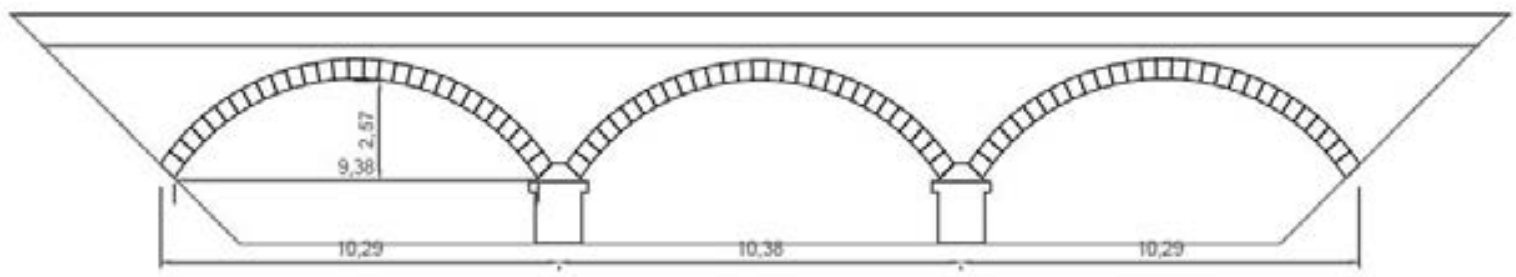

Figure 2: Case study (dimensions in meters).

A two-dimensional limit state model was developed using LimitState:GEO which is designed to rapidly analyze the ultimate limit state for a wide variety of $2 \mathrm{D}$ geotechnical problems by using the computational limit analysis technique named Discontinuity Layout 
Optimization (DLO) [12]. The software was selected due to the reliability of its results when assessing the collapse mechanisms of MABs, while allowing to model the soil parts of the bridge and its interaction with other materials (e.g., concrete, masonry) [13]. Moreover, the software allows fast and computational efficiency which is key when performing probabilistic analysis.

Only the parameters defining the yield surface are required for the material models used by LimitState:GEO. The following models were used to define the different components of the case study: (i) a Mohr-Coulomb model was employed to represent the soil parts of the bridge, namely riverbed and backfill; (ii) fully rigid blocks, where no slip-line can pass through it at any load, were utilized for modelling masonry blocks and foundations; and (iii) cutoff materials were used to model joints, which allows modelling tension cracks or crushing by limiting the tensile or compressive stress, respectively [12].

Load models are used to represent the real loading that a bridge is subjected to. Some studies have been made regarding the reliability of Portuguese MABs, which are based on the documentation provided by the Portuguese railway authorities (Infraestruturas de Portugal) [2]. The load model is composed of four-point loads spaced by $1.6 \mathrm{~m}$. Two distributed loads are also defined within the load mode, but studies have shown that even by not considering them the most unfavorable case scenario is still achieved [14].

By assuming that there is no failure (nor excessive deformation) in the spandrel walls, then the bridge capacity will depend mainly on the arch barrel and the backfill. Therefore, 2D limit state analyses are best suited for in-plane assessment of bridge reliability. Nevertheless, it is worth mentioning that bridges with increased backfill height are more vulnerable to outof-plane failure of the spandrel (i.e., less load carrying capacity) [15].

The water table was assumed to be acting on top of the structure due to the inadequacy of the masonry arch bridge to withstand the design flood (100-year return period) as concluded by the hydraulic modelling [11]. Moreover, studies have been made showing the effects of the water level in $\mathrm{MAB}$, in which for a fully submerged bridge (with backfill fully saturated) a reduction in its load-bearing capacity near $40 \%$ was found [7]. Thus, to have the most unfavorable scenario, all soil materials are considered fully saturated and a water table near the surface level is assumed.
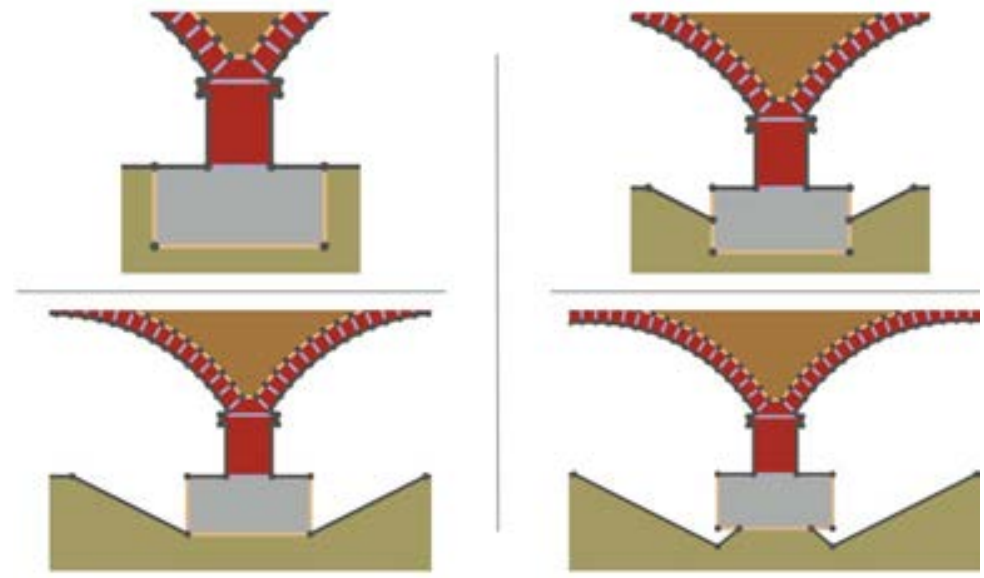

Figure 3: Scour profiles (No scour, minor, moderate, and extensive).

The scour cavity is affected by several factors including soil type, flow velocity and turbulence, and foundation geometry [16]. Studies have been made in which several shapes for local scouring were defined and studied [8].

There are three main forms of scour around foundations, upstream, downstream and at the sides. When analyzing in-plane behavior, only the effects of the local scour due to the separa- 
tion of the flow (i.e., at the sides) will be considered. The profile geometry was defined by considering not only different damage states but scour depths and shape of the foundation. Figure 3 depicts the proposed scour cavities which represent different damage levels (minor, moderate, extensive) which are related to the ratio between scour depth and foundation height (ds/D equal to $0.50,1.00,1.36$ ) [8], [16], [17].

By analyzing the ultimate capacity of the bridge in terms of an adequacy factor (see Figure 4), which is based on how many loads increments the structure can withstand before collapsing, it is possible to evaluate the safety level of the bridge. In the following chapter, a stochastic approach is conducted to evaluate the reliability of the structure under the effects of local scouring.

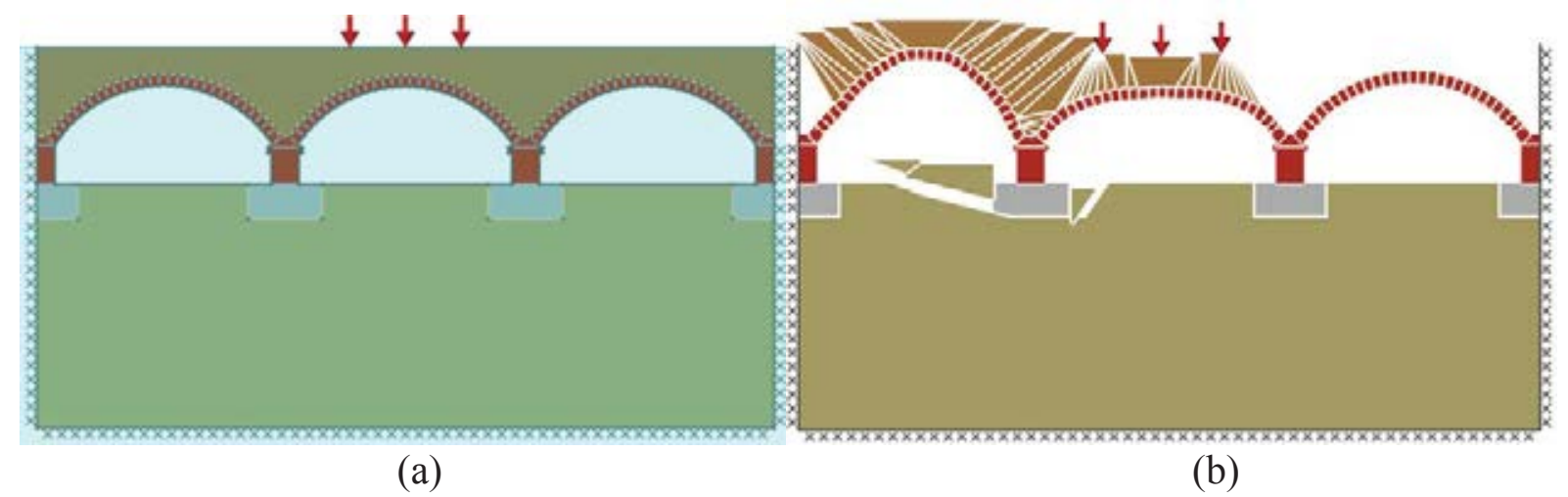

Figure 4: 2D Limit-state model without local scouring (a) geometry (b) failure for an adequacy factor of 4.235

\section{PROBABILISTIC ANALYSIS}

In structural design, there are many uncertainties related to loading and load-carrying capacities. Fundamentally, structures do not have a zero probability of failure due to the random variables involved in the design, construction, and operation processes [18].

To compute the reliability index of the case study, first some random variables that are involved in the load-carrying capacities of the structure must be defined and assessed. Resistance parameters and density of each material comprising the structure are considered. In Table 1, each variable with its distribution type and parameters are presented.

\begin{tabular}{cccccccc}
\hline ID & Description & Element & Nominal Values & Units & CV $(\%)$ & Type & Reference \\
\hline FA $_{S}$ & Friction angle & Soil & 34,61 & $\tan (\varphi)$ & 10,0 & Lognormal & {$[19]$} \\
SD $_{\mathrm{S}}$ & Saturated density & Soil & 20,50 & $\mathrm{kN} / \mathrm{m} 3$ & 5,0 & Lognormal & {$[19]$} \\
$\mathrm{D}_{\mathrm{C}}$ & Density & Concrete & 25,00 & $\mathrm{kN} / \mathrm{m} 3$ & 10,0 & Gaussian & {$[20]$} \\
$\mathrm{SD}_{\mathrm{B}}$ & Saturated density & Backfill & 20,00 & $\mathrm{kN} / \mathrm{m} 3$ & 12,5 & Gaussian & {$[21]$} \\
$\mathrm{C}_{\mathrm{B}}$ & Cohesion & Backfill & 30,00 & $\mathrm{kPa}$ & 15,0 & Gaussian & {$[6]$} \\
$\mathrm{FA}_{\mathrm{B}}$ & Friction angle & Backfill & 30,00 & $\circ$ & 10,0 & Gaussian & {$[6]$} \\
$\mathrm{D}_{\mathrm{M}}$ & Density & Masonry & 16,00 & $\mathrm{kN} / \mathrm{m} 3$ & 10,0 & Gaussian & {$[22]$} \\
\hline
\end{tabular}

Table 1: Random variables used in the probabilistic analysis.

\subsection{Surrogate model}

The use of reliability methods is limited due to the vast computational cost they often require. Therefore, metamodeling techniques (e.g., polynomial chaos, kriging, among others) have been widely used. Comparisons between different surrogate models have been conducted, and Kriging based metamodels using subset simulations (AK-SS [10]) have been proven 
to be efficient to describe non-linear limit state functions, allowing a great representation of the behavior of the function using 19 evaluations [9]. To optimize the probabilistic assessment of the structure by reducing the number of evaluations (i.e., numerical models), a surrogate model was built using UQLab, a general-purpose Uncertainty Quantification framework [23].

The assessment of the load-carrying capacity of a masonry arch bridge can be approximately represented by a non-linear limit state function, as shown traditionally by the Military Engineering Experimental Establishment (MEXE) method. This method has its roots in idealized elastic structural modelling, which mainly depends on geometrical parameters and densities of materials (e.g., masonry and backfill) [24].

Therefore, an experimental design of 20 runs generated by using the Latin Hypercube Sampling Method (LHS) was used [9]. Then, a Kriging metamodel using UQlab was created and validated based on the random variables previously defined. The surrogate model uses a universal trend type, an anisotropic ellipsoidal Matérn 5/2 correlation function, used to define the Gaussian process and cross-validation estimation method. For the validation of the metamodel, two different sources of error estimation were implemented. First, the leave one out method, and second a validation experimental design of 10 runs using LHS; the errors found were $4.11 \mathrm{e}-03$ and $8.28 \mathrm{e}-03$, respectively.

\subsection{Sensitivity analysis}

To reduce the number of relevant variables in the response of the structure, a sensitivity analysis was performed using UQlab. Analysis of covariance (ANCOVA) was used to produce helpful sensitivity indices for both correlated and uncorrelated input variables using a covariance decomposition method [25].
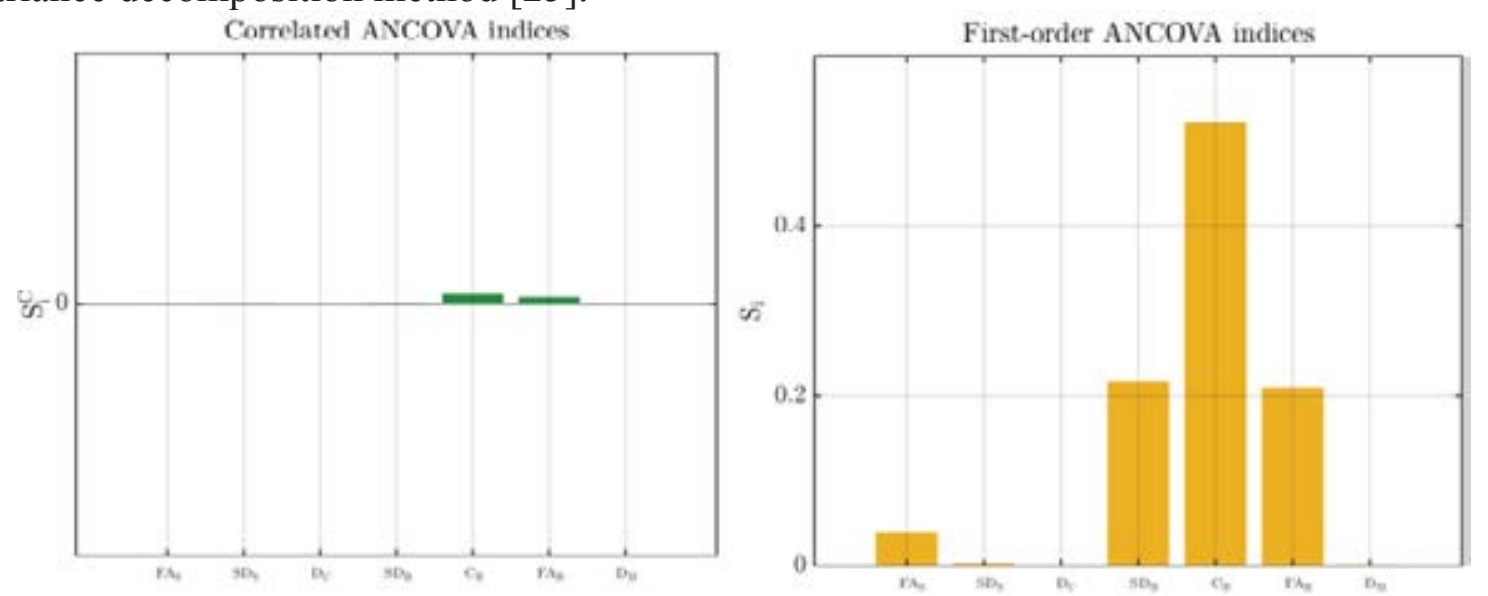

Figure 5: ANCOVA indices

As it can be observed from Figure 5, the parameters with the most influence over the loadcarrying capacity are the ones used to describe the backfill soil. This was expected given that most of the capacity of the bridge for in-plane behavior (and excluding the spandrel) comes from the backfill [15]. Furthermore, the soil underneath the foundation has an impact on the capacity, which is expected as a portion of the soil is being mobilized by the foundation. As the correlated ANCOVA indices are small in magnitude, the correlation among input variables has only a weak effect on the response sensitivity.

Then, the same process used to define the surrogate model is used, but instead of the seven variables, only the main four are used. This gives a more efficient metamodel without compromising its reliability. 


\subsection{Reliability analysis}

By using the surrogate model based on the relevant variables, an experimental design of 10000 simulations using Monte-Carlo (MC) sampling method was generated (Figure 6). Then, a Gumbel distribution was fitted based on the generated histogram of adequacy factors (i.e., collapsing loads), which allowed to define the resistance curve R. Additionally, model uncertainties for limit state models (defined by a Gaussian distribution of mean 1 and COV 1\%), was also considered [6]. The loading curve $\mathrm{S}$ was defined using existing data fitted to a Gumbel distribution, which is described by a mean equal to $184.41 \mathrm{kN}$ and a COV of $9.06 \%$ [2].

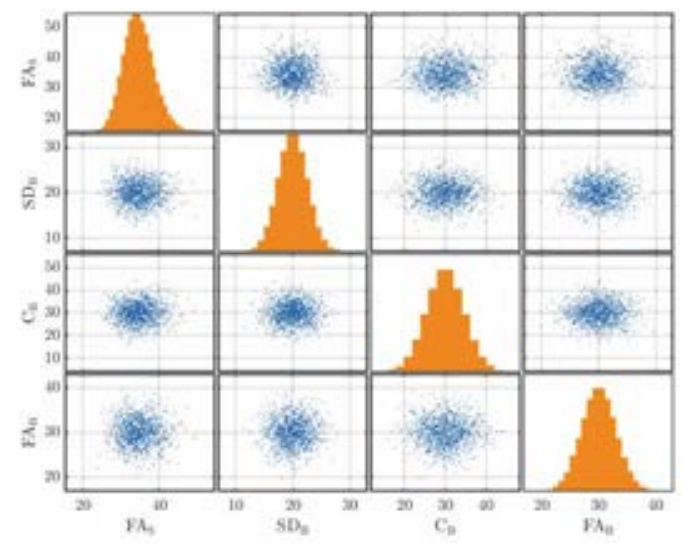

Figure 6: MC experimental design.

To obtain the reliability index of the structure for a given profile of local scour, traditional methods like $\mathrm{MC}$ may require numerous simulations to converge with a satisfactory level of accuracy. Therefore, subset simulation techniques are employed herein to overcome this limitation by solving simpler reliability problems with intermediate thresholds (Figure 7) [26].

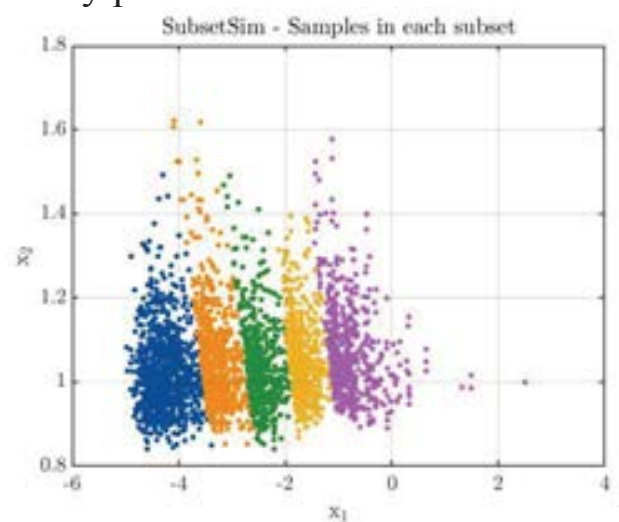

Figure 7: Subset simulation samples discretization.

Once the reliability analysis is completed, the failure probability and reliability index are obtained. In the following chapter, the different results obtained for each scour profile will be presented and discussed.

\section{INFLUENCE OF SCOUR DEPTH IN THE RELIABILITY OF THE STRUCTURE}

Each scour profile produces a different impact on the reliability of the structure, and it is important to understand how changes in the scour depth (ds) in relation to the foundation 
height (D) may affect the load-bearing capacities of the bridge. Next, the results for the different scour scenarios are presented.

First, the sensitivity analysis shows some differences among the scour profiles (see Figure 8 ). It can be seen that the variables related to the backfill are the ones with the most influence on the load-bearing capacity of the bridge (in-plane analysis) [15]. Moreover, due to the remotion of soil at the base of the foundation (i.e., changes ds/D), the parameters related to the soil beneath the river have less influence when the scour hole increases, as can be observed in Figure 9 by the differences between the failure modes for each scour profile.
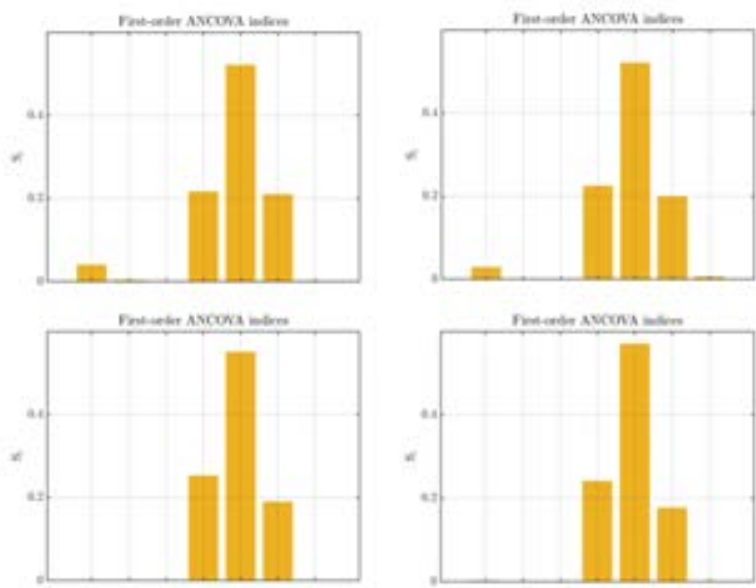

Figure 8: Results of the sensitivity analysis for each scour profile (no scour, minor, moderate, and extensive).

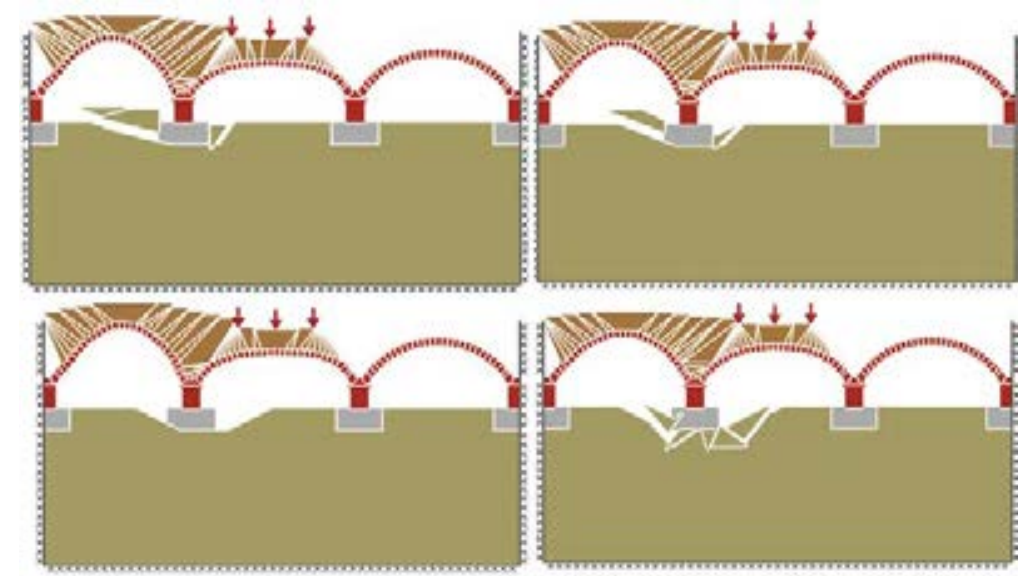

Figure 9: Failure modes of each scour profile (no scour, minor, moderate, and extensive.

Among the different scour scenarios, the failure mode remains largely the same, i.e., in each case, failure of the backfill is achieved by incrementing the railroad load applied at surface level. Moreover, failure at the riverbed is reached due to the mobilization of the foundation. Meanwhile, both arch failures show the characteristic shape of the hinging mechanism [27].

Then, the respective surrogate models are defined, and the capacity curve of the structure for each of the scour profiles are built (see Figure 10). It can be observed that the capacity of the bridge decreases with each increment of the scour depth. As expected, the loss of bearing capacity for scour depth values lower than the foundation height is slight, i.e., the capacity curve largely maintains its properties which indicates a slight decrease in the bridge reliability index [8]. 


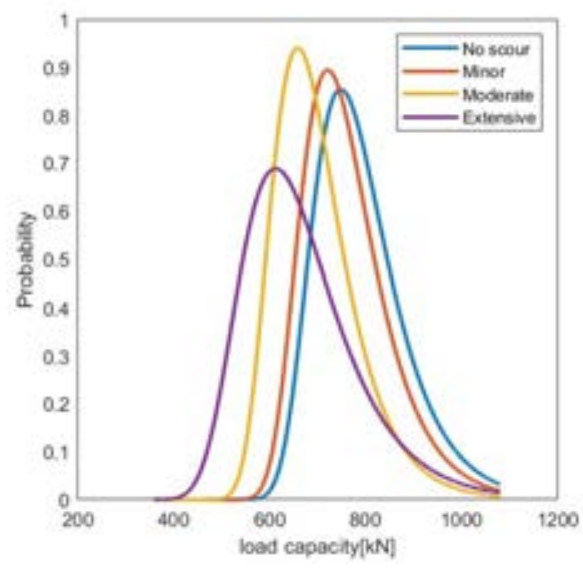

Figure 10: Resistance curve R of each scour profile.

However, when analyzing the extensive scour profile, the capacity curve changes drastically which may be occasioned by failure of the soil under the foundation. Finally, the values of reliability and failure probability are plotted against the scour depth (ds/D) in Figure 11.

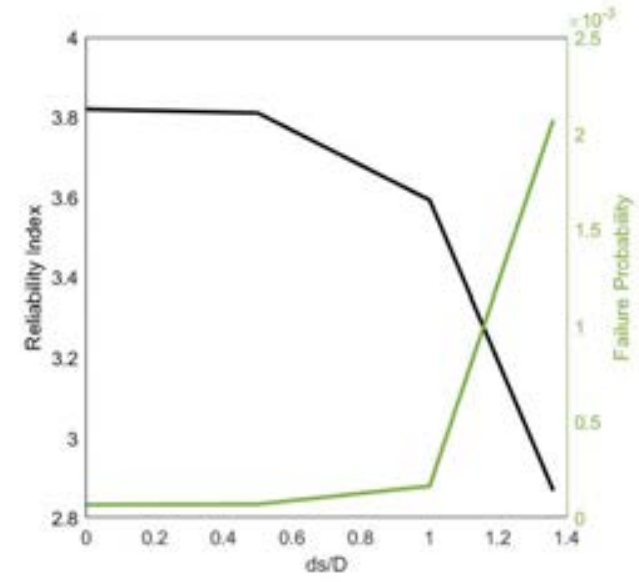

Figure 11: Reliability index and probability failure against scour depth

From Figure 11 it can be seen that the reliability index decreases greatly when the local scour starts to extend below the foundation. This situation may cause problems with extensive settlements of the bridge which may induce instability on the arch barrel and consequently bridge collapse [8]. For none of the scour profiles the structure fulfills the target reliability for safety, i.e. $\beta_{\text {target }}=4.3$ for structures with consequences involving high human and economic losses, according to the NP 1990 [28].

\section{CONCLUSIONS}

The present work established an efficient framework for reliability assessment of MAB subject to flood-induced scour. The methodology was validated through a case study bridge located in Portugal. Based on the obtained results, the following conclusions can be made:

- By using surrogate model techniques, it is possible to perform several numbers of experiments, that otherwise would be time-consuming and would demand high computational cost, with a satisfactory level of reliability. Thus, optimizing and improving probabilisticanalyses. Regarding the study of the reliability of MAB, it was possible to examine different scenarios of local scouring by analyzing different random variables at an efficient computational cost. 
- By performing a sensitivity analysis, the most relevant variables when assessing the bridge capacity were obtained and validated by literature. As discussed before, the soil parameters used to describe the behavior of the backfill are the ones that have the most impact when computing the load-bearing capacity of the in-plane performance of a MAB [15].

- To understand the behavior of the bridge under local scouring, the ultimate limit state function was defined by considering the randomness of the bridge loading capacity and different scour profiles, which allowed assessing the bridge performance under floods. In each of the proposed scenarios, failure of the backfill was achieved by incrementing the railroad load applied at the surface level. Moreover, the arches under the mobilized portion of the backfill presented shapes that resemble failure by hinging mechanism [27].

- As expected, the loss of bearing capacity becomes considerable when the scour depth surpasses the foundation depth. Failure of the soil under the foundation may explain the differences of the capacity curve, as found for the extensive scour scenario. It should be noted that the variation of the lateral erosion (i.e., dimension below the foundation) for the same scour depth, even though was not considered, influences the bridge capacity [8].

- The case study presented an initial reliability of 3.82 which indicates a probability of failure of $6.68 \mathrm{e}-05$. When increasing the scour depth up to 1.36 times the foundation height (extensive level), the reliability index decreased up to 2.87 with a failure probability of 2.07e-03. Consequently, none of the scour scenarios fulfill the target reliability in the codes [28], which indicates that the bridge presents a poor performance under flooding events.

This study represents the first approach to assess the reliability of MAB subject to the effects of scour and floods. It is recommended to expand upon this work by analyzing out of plane behavior and investigate the effects of the bridge geometry and other flood-related effects that may influence the bridge performance. Finally, vulnerability analysis considering direct and indirect consequences may provide useful information for bridge management and decision making.

\section{ACKNOWLEDGMENTS}

This work was partly financed by FCT / MCTES through national funds (PIDDAC) under the R\&D Unit Institute for Sustainability and Innovation in Engineering Structures (ISISE), under reference UIDB / 04029/2020.

The second author would like to thank FCT - Portuguese Scientific Foundation for the research grant SFRH/BD/144749/2019.

This project has received funding from the European Union's Horizon 2020 research and innovation programmed under grant agreement No 769255. This document reflects only the views of the author(s). Neither the Innovation and Networks Executive Agency (INEA) nor the European Commission is in any way responsible for any use that may be made of the information it contains.

\section{REFERENCES}

[1] L. Quirk, J. Matos, J. Murphy, and V. Pakrashi, "Visual inspection and bridge management," Struct. Infrastruct. Eng., vol. 2479, no. July, pp. 1-13, 2017, doi: 10.1080/15732479.2017.1352000. 
[2] V. N. Moreira, J. Fernandes, J. C. Matos, and D. V. Oliveira, "Reliability-based assessment of existing masonry arch railway bridges," Constr. Build. Mater., vol. 115, pp. 544-554, 2016, doi: 10.1016/j.conbuildmat.2016.04.030.

[3] A. Decò and D. M. Frangopol, "Risk assessment of highway bridges under multiple hazards," J. Risk Res., vol. 14, no. 9, pp. 1057-1089, 2011, doi: 10.1080/13669877.2011.571789.

[4] L. Deng, W. Wang, and Y. Yu, "State-of-the-Art Review on the Causes and Mechanisms of Bridge Collapse," J. Perform. Constr. Facil., vol. 30, no. 2, p. 04015005, 2015, doi: 10.1061/(asce)cf.1943-5509.0000731.

[5] F. T. Ekuje, "Bridge Scour - Climate Change Effect," 2018.

[6] B. Conde, J. C. Matos, D. V. Oliveira, and B. Riveiro, "Probabilistic-based structural assessment of a historic stone arch bridge," Struct. Infrastruct. Eng., vol. 0, no. 0, pp. 1-13, 2020, doi: 10.1080/15732479.2020.1752261.

[7] K. M. Hulet, C. C. Smith, and M. Gibert, "Load-carrying capacity of flooded masonry arch bridges," Proc. Inst. Civ. Eng. Bridg. Eng., vol. 159, no. 3, pp. 97-103, 2006, doi: 10.1680/bren.2006.159.3.97.

[8] P. Zampieri, M. A. Zanini, F. Faleschini, L. Hofer, and C. Pellegrino, "Failure analysis of masonry arch bridges subject to local pier scour," Eng. Fail. Anal., vol. 79, no. May, pp. 371-384, 2017, doi: 10.1016/j.engfailanal.2017.05.028.

[9] H. Guimarães, J. C. Matos, and A. A. Henriques, "An innovative adaptive sparse response surface method for structural reliability analysis," Struct. Saf., vol. 73, pp. 12 28, 2018, doi: 10.1016/j.strusafe.2018.02.001.

[10] X. Huang, J. Chen, and H. Zhu, "Assessing small failure probabilities by AK-SS: An active learning method combining Kriging and Subset Simulation," Struct. Saf., vol. 59, pp. 86-95, 2016, doi: 10.1016/j.strusafe.2015.12.003.

[11] Infraestruturas de Portugal, "Modernização da Linha do Norte- Trecho Vila Franca de Xira (Norte) - Azambuja," 2001.

[12] LimitState: GEO Manual, "LimitState: GEO Manual,” vol. 44, no. 0, 2010.

[13] M. Gilbert, C. C. Smith, and T. J. Pritchard, "Masonry arch analysis using discontinuity layout optimisation," Proc. Inst. Civ. Eng. Eng. Comput. Mech., vol. 163, no. 3, pp. 155-166, 2010, doi: 10.1680/eacm.2010.163.3.155.

[14] S. De Santis, "Load-carrying capability and seismic assessment of masonry bridges," Engineering, no. February, 2011.

[15] B. Pulatsu, E. Erdogmus, and P. B. Lourenço, "Influence of soil-backfill depth on the strength and behavior of masonry arch bridges in the transverse direction," 13th North Am. Mason. Conf., no. June, pp. 15-25, 2019.

[16] B. A. Vijayasree, T. I. Eldho, B. S. Mazumder, and N. Ahmad, "Influence of bridge pier shape on flow field and scour geometry," Int. J. River Basin Manag., vol. 17, no. 1, pp. 109-129, 2019, doi: 10.1080/15715124.2017.1394315.

[17] S. Mitoulis and S. Argyroudis, "Survey for bridge restoration after floods," no. January, 2021.

[18] A. S. Nowak and K. R. Collins, Reliability of structures. Mc Graw Hill, 2000. 
[19] JCSS PROBABILISTIC MODEL CODE, "Section 3.7: Soil properties," JCSS Probabilistic Model Code, no. August, 2006.

[20] T. Choudhury and H. B. Kaushik, "Treatment of uncertainties in seismic fragility assessment of RC frames with masonry infill walls," Soil Dyn. Earthq. Eng., vol. 126, no. July, p. 105771, 2019, doi: 10.1016/j.soildyn.2019.105771.

[21] P. Zampieri, M. A. Zanini, and F. Faleschini, "Derivation of analytical seismic fragility functions for common masonry bridge types: methodology and application to real cases," Eng. Fail. Anal., vol. 68, pp. 275-291, 2016, doi: 10.1016/j.engfailanal.2016.05.031.

[22] L. Su, X. long Li, and Y. pang Jiang, "Comparison of methodologies for seismic fragility analysis of unreinforced masonry buildings considering epistemic uncertainty," Eng. Struct., vol. 205, no. October 2019, p. 110059, 2020, doi: 10.1016/j.engstruct.2019.110059.

[23] S. Marelli and B. Sudret, "UQLab: a Framework for Uncertainty Quantification in MATLAB," in The 2nd International Conference on Vulnerability and Risk Analysis and Management (ICVRAM 2014), 2014, pp. 2554-2563, doi: 10.1061/9780784413609.257.

[24] J. Wang and C. Melbourne, "Mechanics of MEXE method for masonry arch bridge assessment," Proc. Inst. Civ. Eng. Eng. Comput. Mech., vol. 163, no. 3, pp. 187-202, 2010, doi: 10.1680/eacm.2010.163.3.187.

[25] C. Xu and G. Z. Gertner, "Uncertainty and sensitivity analysis for models with correlated parameters," Reliab. Eng. Syst. Saf., vol. 93, no. 10, pp. 1563-1573, 2008, doi: 10.1016/j.ress.2007.06.003.

[26] S. K. Au and J. L. Beck, "Estimation of small failure probabilities in high dimensions by subset simulation," Probabilistic Eng. Mech., vol. 16, no. 4, pp. 263-277, 2001, doi: 10.1016/S0266-8920(01)00019-4.

[27] B. Pulatsu, E. Erdogmus, and P. B. Lourenço, "Comparison of in-plane and out-ofplane failure modes of masonry arch bridges using discontinuum analysis," Eng. Struct., vol. 178, no. August 2018, pp. 24-36, 2019, doi: 10.1016/j.engstruct.2018.10.016.

[28] NP EN 1990: 2009, "Norma Portuguesa - Eurocódigo 0 - Bases para o projeto de estruturas,” Inst. Port. da Qual., vol. 1999, p. 88, 2009. 